\title{
Current Mental Health Clients' Attitudes Regarding Religion and Spirituality in Treatment: A National Survey
}

\author{
Holly K. Oxhandler ${ }^{1, *(\mathbb{D})}$, Kenneth I. Pargament ${ }^{2} \mathbb{D}$, Michelle J. Pearce ${ }^{3}$, Cassandra Vieten ${ }^{4}$ \\ and Kelsey M. Moffatt ${ }^{1}$ \\ 1 Diana R. Garland School of Social Work, Baylor University, Waco, TX 76798, USA; kelsey_podley@baylor.edu \\ 2 Department of Psychology, Bowling Green State University, Bowling Green, OH 43403, USA; \\ kpargam@bgsu.edu \\ 3 Graduate School, University of Maryland, Baltimore, MD 21201, USA; michelle.pearce@umaryland.edu \\ 4 Clarke Center for Human Imagination, Department of Physical Sciences, University of California San Diego, \\ La Jolla, CA 92093-0021, USA; cevieten@ucsd.edu \\ * Correspondence: holly_oxhandler@baylor.edu
}

check for updates

Citation: Oxhandler, Holly K., Kenneth I. Pargament, Michelle J. Pearce, Cassandra Vieten, and Kelsey M. Moffatt. 2021. Current Mental Health Clients' Attitudes Regarding Religion and Spirituality in Treatment A National Survey. Religions 12: 371. https://doi.org/10.3390/rel12060371

Academic Editors: Hans Zollner, Jesse Fox and Evan Copello

Received: 31 March 2021

Accepted: 13 May 2021

Published: 21 May 2021

Publisher's Note: MDPI stays neutral with regard to jurisdictional claims in published maps and institutional affiliations.

Copyright: (c) 2021 by the authors. Licensee MDPI, Basel, Switzerland. This article is an open access article distributed under the terms and conditions of the Creative Commons Attribution (CC BY) license (https:// creativecommons.org/licenses/by/ $4.0 /)$.

\begin{abstract}
Over the last several years, there has been a growing interest in clients' views toward integrating their religion and spirituality (RS) into mental health treatment. However, most of these studies have been limited to small samples and specific populations, regions, and/or clinical issues. This article describes the first national survey of current mental health clients across the US regarding their attitudes towards integrating their RS in treatment using a revised version of the Religious/Spiritually Integrated Practice Assessment Scale-Client Attitudes, version 2 (RSIPAS-CAv2) with a sample of 989 clients. Our findings indicate mental health clients have overwhelmingly positive attitudes regarding integrating their RS into mental health treatment. Additionally, we explored what background characteristics predict clients' attitudes toward this area of practice and found the top predictor was their intrinsic religiosity, followed by whether they had previously discussed RS with their current provider, age, gender, organized and non-organized religious activities, belief in God/Higher Power, and frequency of seeing their mental health provider. The reliability and validity of the RSIPAS-CAv2 was also explored and this scale is recommended for future use. Implications and recommendations for practice, research, and future training efforts are discussed.
\end{abstract}

Keywords: religion; spirituality; mental health; client preferences; therapy; counseling; social work; psychology; psychiatry; attitudes; depression; anxiety

\section{Introduction}

There has been growing attention to mental health clients' religion and spirituality (RS) as a critical component to be addressed in treatment across helping professions (American Psychological Association 2010; American Association for Marriage and Family Therapy 2012; American Counseling Association 2014; American Nurses Association 2015; National Association of Social Workers 2017). Researchers and clinicians have recognized the salient role RS play in clients' lives, appearing in both positive and negative forms of coping (Exline 2013; Pargament 2007), various spiritual needs (van Nieuw AmerongenMeeuse et al. 2020), heightened self-esteem (Colbert et al. 2009), improved health and mental health treatment outcomes (Koenig et al. 2001, 2012), and greater life satisfaction (Leondari and Gialamas 2009). Across disciplines, a growing number of scholars as well as ethical standards now encourage clinicians to integrate clients' RS into treatment (Hodge 2006; Hook et al. 2010; Oxhandler et al. 2015; Oxhandler and Pargament 2014; Pargament 2007; Rose et al. 2001; Smith et al. 2007; Worthington et al. 2011).

Although several definitions exist for RS, a commonly used definition of religion is "the search for significance that occurs within the context of established institutions that are designed to facilitate spirituality," with spirituality being "the search for the sacred" 
(Pargament et al. 2013, pp. 14-15). Although these terms are distinct, adults in the United States (US) tend to see these terms as overlapping, with over half identifying as moderately/very religious and 65\% identifying as moderately/very spiritual (Smith et al. 2016). Further, Oxhandler et al. (2018a) note a moderate, positive correlation $(r=0.56, p<0.001)$ between US adults identifying as religious and spiritual, emphasizing this overlap between the two terms for many (but not all) that is often tied to one's "thoughts, experiences, and behaviors that arise from the search for the sacred" (Hill et al. 2000, p. 66).

To date, the US is one of the most religious industrial countries in the world (Pew Research Center 2012). About nine out of 10 of US adults believe in a higher power and over half pray daily (Pew Research Center 2015), often for healing themselves or others (Levin 2016). With RS's important role in individuals' lives and RS serving "among the most important factors which structure human experience, beliefs, values, and behavior, as well as illness patterns" (Lukoff et al. 1992, p. 56), RS certainly have a role in the lives of many clients, particularly highly religious clients. As Pearce (2016) notes:

Clients can't check their worldviews, spirituality, or values at our door any more than we can choose to leave our hands and feet behind when we go to work. A religious identity and worldview are integral aspects of how religious clients think about, experience, respond to, and take action upon their world. (Pearce 2016, p. 3)

Thus, for mental health care providers to remain client-centered and culturally competent, they must address this area of clients' lives with humility, sensitivity, and an awareness of current trends in client views. In order to do so, a better understanding of clients' views toward discussing their RS in mental health care is warranted.

\subsection{Client Attitudes toward RS in Mental Health Treatment}

When given the option, many clients want to integrate RS into treatment, view RS as important for discussion in counseling, and often prefer for the practitioner to bring up the topic (Cragun and Friedlander 2012; Harris et al. 2016; Leitz and Hodge 2013; Lyon and Wimmer 2005; Oxhandler et al. 2018b; Morrison et al. 2009; Rose et al. 2001; Stanley et al. 2011; Tepper et al. 2001; Weld and Eriksen 2007). These findings extend to individual counseling (Erickson et al. 2002; Lindgren and Coursey 1995; Lyon and Wimmer 2005), group counseling (Post et al. 2014), and marital counseling (Bannister et al. 2015). Clients have communicated an expectation for therapists to be sensitive to and respectful of their beliefs and values, and to remain open to discussing them in treatment (Belaire and Young 2002; D'Souza 2002; Oxhandler et al. 2018b; Post and Wade 2009). This sensitivity and openness for discussion around the clients' RS can help to strengthen the therapeutic alliance and bolster treatment outcomes (Knox et al. 2005; Wade et al. 2007).

\subsubsection{Client Characteristics That Influence Client Preference}

When it comes to client preferences with respect to integrating their RS into treatment, previous studies highlight certain characteristics and demographic variables associated with a preference for such integration. Namely, women (Erickson et al. 2002; Schaffner and Dixon 2003), racially and ethnically diverse populations (Atkinson and Gim 1989; Crosby and Bossley 2012; Rogers et al. 2012; Wang et al. 2005), and older adults (Stanley et al. 2011) may be more likely to prefer to have their RS beliefs / practices considered in treatment.

Not surprisingly, highly religious clients prefer such integration, although they tend to be reluctant to pursue secular mental health care (Mayers et al. 2007), typically seeking support from a religious leader (Crosby and Bossley 2012). Still, many mental health clients who identify as highly religious or who hold strong religious values want to discuss RS in treatment and for the therapist to initiate the conversation (Harris et al. 2016; Oxhandler et al. 2018b; Stanley et al. 2011; Weld and Eriksen 2007). These clients may also be apprehensive about opening up to clinicians if they perceive the clinician as not sharing the client's RS values (Carlisle 2015; Cragun and Friedlander 2012). For clients who identify as less religious, results vary across studies, as some indicate RS is important to 
discuss but do not have a strong preference for integration in treatment as compared to those who identify as highly religious (Arnold et al. 2002; Walker et al. 2011). As one might expect, clients who identify as atheist are less likely to prefer such integration (Baker and Cruickshank 2009).

Clients' faith tradition also yields different preferences regarding RS help-seeking. In Hathaway's (2005) study, among 236 church members from Southern Baptist, Catholic, Methodist, and Mennonite churches, both religious and denominational variables influenced clients' help-seeking attitudes. Catholics and Methodists were more likely to seek out secular counseling than Baptists and Mennonites, with Baptists more likely to seek out psychological help from Christian resources (Christian counselor or church leaders) and Mennonites having the lowest scores regarding help-seeking (Hathaway 2005).

In addition to denominational influences, clients' RS practices may influence their preferences. Namely, those who engage in RS practices, including prayer or meditation, hold greater expectations and preferences for discussing their RS beliefs and practices in treatment (Laudet 2003; Privette et al. 1994; Weld and Eriksen 2007), including prayer during sessions (Daaleman and Nease 1994; King and Bushwick 1994).

For some clients, there is also a desire to see a counselor that shares a similar RS belief system (Belaire and Young 2002; Harris et al. 2016; Kelly et al. 1996), particularly among Christian (Erickson et al. 2002; Gass 1984; Godwin and Crouch 1989; Guinee and Tracey 1997) and Orthodox Jewish clients (Wikler 1989). Yet, other studies yield mixed results regarding client preferences for being matched to a therapist with similar RS beliefs (Mayers et al. 2007). Most recently, 69\% of clients in one national survey agreed they were willing to see a therapist with different RS beliefs, with 7\% disagreeing (Oxhandler et al. 2018b). Thus, past studies suggest mixed results related to client preferences for their therapist's faith tradition.

\subsubsection{Limitations of Previous Studies}

While these studies pioneered the discussion of clients' preferences towards integrating RS into mental health treatment, the previous research has significant limitations. Several of these small-scale studies are specific to particular regions, demographic factors (Cashwell et al. 2001; Morrow et al. 1993; Post et al. 2014; Schaffner and Dixon 2003), or faith traditions (Baker and Cruickshank 2009; Bannister et al. 2015; Belaire et al. 2005; Kelly et al. 1996; Walker et al. 2011; Weld and Eriksen 2007). Due to the specificity and convenience sampling, in addition to the qualitative nature of many of these studies that is designed to capture depth over breadth, the data in previous studies are not generalizable to larger client samples receiving mental health services across the US.

To our knowledge, just one study to date examined a large, national survey of mental health clients' attitudes toward integrating RS. In 2015, Oxhandler et al. (2018b) utilized Qualtrics' crowd sourcing services to recruit a sample of equally younger and older adults regarding their RS, views of God, RS coping, as well as levels of stress, anxiety, and/or depression. This survey also contained the newly developed Religious/Spiritually Integrated Practice Assessment Scale-Client Attitudes (RSIPAS-CA; Oxhandler et al. 2018b), which mirrored the original RSIPAS's (Oxhandler and Parrish 2016) Attitudes subscale that measures practitioners' views on integrating clients' RS. The original RSIPAS had established content, criterion, discriminant, convergent, and factorial validity (Oxhandler and Parrish 2016) and has been used in a number of studies related to mental health care providers' integration of clients' RS in practice (Crabtree et al. 2020; Oxhandler and Parrish 2018; Pearce et al. 2020). Oxhandler et al. (2018b) adapted the items from measuring practitioners' views of integrating clients' RS in practice to clients' views of such integration in the RSIPAS-CA, while retaining the essence of the items. The original RSIPAS-CA was established with experts in the field of RS and mental health, and the current study's slight adaptation of the RSIPAS-CAv2 included a review from a panel of interdisciplinary experts in this field to support the instrument's content validity (Oxhandler et al. 2021b). 
Of the 1047 who responded to the 2015 survey, 245 had seen a therapist for various clinical issues, with only 27 doing so in the last month, 31 in the last year, 44 in the last one to five years, and 143 over 5 years ago. Although this survey provided national quantitative data on client attitudes related to integrating their RS, the equal younger/older adult sample was not representative in age and most had not seen a therapist recently, risking recall bias in their responses. Further, many of the items ask respondents about clients more generally (e.g., It is important for a therapist to know how to discuss clients' RS in mental health therapy), rather than assessing the respondent's direct experience (e.g., It is important for my therapist to know how to discuss my RS in mental health therapy). No attempts were made to discern characteristics that predicted their views.

\subsection{Current Study}

The purpose of the current study was to assess a national sample of current mental health clients' attitudes toward integrating RS into treatment and identify what characteristics predict such attitudes. Utilizing a slightly modified version of the RSIPAS-CA scale (Oxhandler et al. 2018b)-labeled as RSIPAS-CA, version 2 (RSIPAS-CAv2) - the current study specifically surveyed mental health clients who had seen a mental health care provider in the past month. The following research questions guided our study: (1) What is the reliability and factorial validity of the revised RSIPAS-CAv2?; (2) What are clients' attitudes toward integrating RS into mental health treatment?; and (3) What client characteristics are predictive of more positive attitudes toward integrating RS into mental health treatment?

\section{Methods}

We first revised the original RSIPAS-CA items to be more reflective of the client's own personal experience, while retaining the essence of the original items, and obtained feedback from a panel of expert reviewers described in Oxhandler et al. (2021b). The resulting adapted 10 items were measured with the same a five-point Likert scale used in the original study (Oxhandler et al. 2018b), ranging from 1 = strongly disagree to $5=$ strongly agree. The final, revised items used in this study are included in the results.

The RSIPAS-CAv2 was then included with other instruments and items in a national survey of current mental health clients. The survey was considered exempt by the first author's institutional review board. Specific to this study, in addition to the RSIPAS-CAv2, we included the Duke University Religious Index (DUREL; Koenig and Büssing 2010) given previous findings that intrinsic religiosity was the primary predictor of practitioners' preferences for integrating clients' RS (Oxhandler et al. 2015; Oxhandler 2017) and previous research suggesting frequency of engaging in religious practices is related to an increase in clients' preferences for integrating their RS (Weld and Eriksen 2007).

As described in Oxhandler et al. (2021b), Qualtrics' crowdsourcing services were contracted by the research team to obtain a sample of approximately 1000 US adults who had seen a mental health care provider (e.g., clinical social worker, psychologist, counselor, therapist, psychiatrist, etc.) within the last month, as determined by multiple screening questions throughout the survey. Data collection occurred between August and October 2018, and given that Qualtrics requires all responses to be complete, there were no missing data.

To answer our first research question, SPSS 25 was utilized to determine the RSIPASCAv2 Cronbach's alpha, and Mplus was used to test the hypothesized one-factor structure of this revised tool by conducting a confirmatory factor analysis (CFA) using Kline's (2016) recommended fit indices. To answer our second and third questions, descriptive analyses, assumption checks, and a multiple regression analysis were conducted using SPSS.

For descriptive reporting, responses to the RSIPAS-CAv2 were collapsed into the following categories: disagree/strongly disagree, neutral, and agree/strongly agree. Both bivariate and multivariate analyses were utilized to identify background characteristics related to clients' attitudes toward integrating their RS into treatment, as measured by 
their RSIPAS-CAv2 score. Continuous independent variables included age and the DUREL intrinsic religiosity score. Dichotomous independent variables included region (dummy coded for Northeast, Midwest, South, and West), gender (coded as female and not female), race (coded as White or non-White), frequency of seeing a therapist (coded as never/rarely or at least a few times a month), DUREL organized religious activities (ORA; frequency of attending religious meetings, coded never/rarely or at least a few times a month), DUREL non-organized religious activities (NORA; frequency of private religious activities, coded as never/rarely or at least once a week), religious affiliation (coded as Abrahamic [Christian/Jewish/Muslim] or non-Abrahamic/none), belief in God or Higher Power (coded as yes/unsure or no), and whether the client's RS beliefs or practices have been discussed with their current therapist (coded as yes or no).

\section{Results}

A total of 2854 individuals who previewed the survey responded to whether they were currently seeing a mental health care provider. Specifically, of those 2854 individuals, 1246 saw a mental health care provider in the last month, although 257 were removed for various reasons described in Oxhandler et al. (2021b), resulting in a final sample of 989 current mental health clients. As noted in Table 1, the sample mostly identified as male $(52.2 \%)$ and White $(76.8 \%)$ with an average age being in the mid-40s $(M=45.6, S D=16.3)$, and was representative across the four US regions. Further, when asked to identify their primary clinical issues (up to three), the largest proportion indicated depression (54.4\%), anxiety $(49.9 \%)$, stress $(16.6 \%)$, anger $(15.4 \%)$, and bipolar disorder $(14.5 \%)$, with other clinical issues described in Oxhandler et al. (2021b).

Table 1. Background Characteristics of Clients $(n=989)$.

\begin{tabular}{lcc}
\hline Characteristic & $\boldsymbol{M}$ & SD \\
\hline Age (years) & 45.6 & \% \\
\hline & & \\
\hline Gender & 471 & 47.6 \\
Female & 516 & 52.2 \\
Male & 2 & 0.2 \\
Other & & \\
\hline Race/Ethnicity & 118 & 11.9 \\
African American/Black & 18 & 1.8 \\
American Indian/Alaskan Native & 22 & 2.2 \\
Asian/Pacific Islander & 63 & 6.4 \\
Hispanic/Latinx & 760 & 76.8 \\
White & 8 & 0.8 \\
Other & & \\
\hline Religious preference & 319 & 32.3 \\
Protestant & 207 & 20.9 \\
Catholic & 51 & 5.2 \\
Jewish & 15 & 1.5 \\
Buddhist & 6 & 0.6 \\
Hindu & 2 & 0.2 \\
Other Eastern Religion & 19 & 1.9 \\
Muslim & 86 & 8.7 \\
Orthodox-Christian & 17 & 1.7 \\
Native American & 53 & 5.4 \\
Inter-Nondenominational & 50 & 5.1 \\
Don't Know/Other & 58 \\
Other & 106 & \\
None & & \\
\hline
\end{tabular}


Table 1. Cont.

\begin{tabular}{lcc}
\hline Characteristic & M & SD \\
\hline Were your RS beliefs brought up in therapy? & & \\
Yes, brought up by client & 415 & 42.0 \\
Yes, brought up by therapist & 256 & 25.9 \\
No, but wish they had been discussed & 94 & 9.5 \\
$\quad$ No, glad they were not discussed & 224 & 22.6 \\
\hline To what extent do you consider yourself a religious person? & & \\
$\quad$ Moderately/very religious & 550 & 55.6 \\
\hline To what extent do you consider yourself a spiritual person? & & 70.4 \\
$\quad$ Moderately/very spiritual & 696 & 83.0 \\
Do you believe in God or a Higher Power?: Yes & 821 & \\
\hline
\end{tabular}

\subsection{Reliability and Validity of RSIPAS-CAv2}

The preliminary, 10-item RSIPAS-CAv2's Cronbach's alpha was 0.91, which is considered excellent (Kline 2016). Item 6, which proved to be problematic in the original RSIPAS-CA (Oxhandler et al. 2018b), also generated some concern, with a 0.006 increase in the alpha if the item was removed. We retained it at this point in the study given the improved wording of the scale items and relatively low impact on the scale's alpha if it were removed.

The initial CFA to test this a priori one-factor scale demonstrated that although item 6 had a higher loading ( 0.44 instead of 0.17 in the initial study; Oxhandler et al. 2018b), it again fell below Comrey and Lee's (1992) recommended 0.45. As a result, item 6 was removed and the baseline CFA item loadings can be found in Figure 1. The same correlated error terms were recommended in the modification indices, including between items 8 and 10, 7 and 9, as well as 2 and 3. The CFA result of this final, nine-item RSIPAS-CAv2 with the correlated error terms (Figure 2) indicated a $\chi^{2}(24, n=989)=249.33, p<0.001$, a root mean square error of approximation (RMSEA) of $0.097(p<0.001)$, which is considered a mediocre fit with this sample, with a $90 \%$ confidence interval between 0.087 to 0.109 . The comparative fit index (CFI) and Tucker-Lewis index (TLI) were 0.99 and 0.98 , respectively (Table 2).

Upon removing item 6, the final Cronbach's alpha for this nine-item scale was 0.92, which is considered excellent and higher than the original study ( $\alpha=0.89$; Oxhandler et al. 2018b). The final average score of the RSIPAS-CAv2 with this sample of current mental health clients across the US was $31.82(S D=8.61$, range: 9-45).

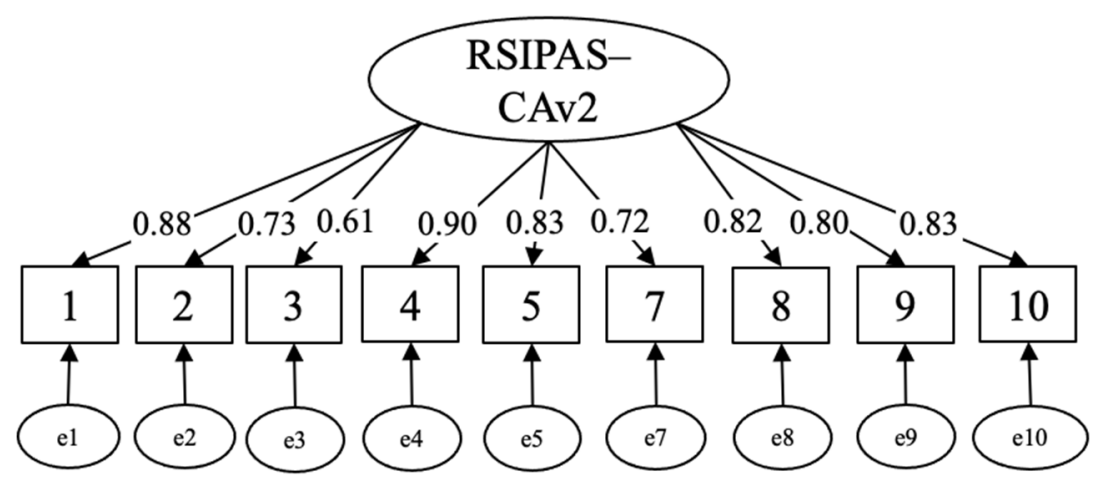

Figure 1. Baseline Hypothesized Model with Standardized Loadings. RSIPAS-CAv2 = Religious/Spiritually Integrated Practice Assessment Scale-Client Attitudes, version 2. 


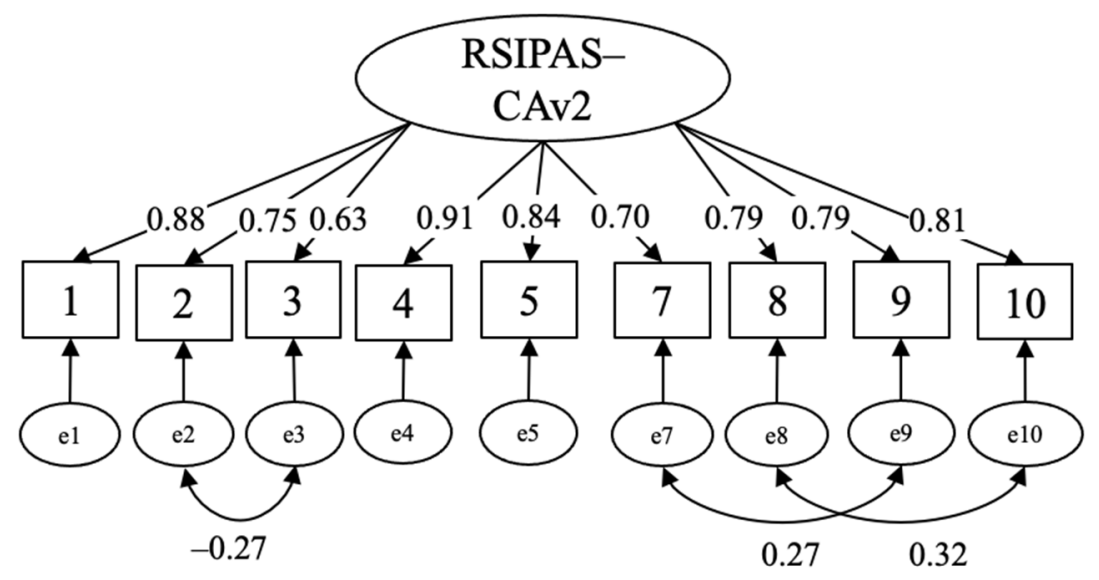

Figure 2. Final Model with Standardized Loadings and Correlated Error Terms. RSIPAS-CAv2 = Religious/Spiritually Integrated Practice Assessment Scale-Client Attitudes, version 2. As compared to the first study (Oxhandler et al. 2018b), seven of the current study's item loadings increased between 0.03 and 0.11 , items 3 and 5 both dropped by 0.03 , and item 7 remained at 0.70 . This suggests our sample had a better fit for the revised items, which makes sense given our focus on current clients rather than a sample that mostly last saw a therapist years ago. Item 6's loading increased from 0.17 in the original study to 0.44 in the current study but did not meet the 0.45 threshold we had set for item retention (Comrey and Lee 1992) and was removed.

Table 2. Summary of CFA Fit Results for Religious/Spiritually Integrated Practice Assessment Scale-Client Attitudes v2 (RSIPAS-CAv2).

\begin{tabular}{cccccccccc}
\hline Model & Items & $d f$ & $x^{2}$ & $p$ & $\chi^{2} / d f$ & RMSEA [90\% CI] & CFI & TLI \\
\hline Baseline CFA & 9 & 27 & 485.89 & 0.00 & 18.00 & $0.131[0.121,0.141]$ & 0.974 & 0.965 \\
\hline Final CFA & 9 & 24 & 249.33 & 0.00 & 10.39 & $0.097[0.087,0.109]$ & 0.987 & 0.981 \\
\hline
\end{tabular}

The baseline CFA includes all items except item 6 due to it falling below 0.45 . RMSEA = root mean square error of approximation; $\mathrm{CI}=$ confidence interval; $\mathrm{CFI}=$ comparative fit index; $\mathrm{TLI}$ = Tucker-Lewis index.

\subsection{Client Attitudes toward RS Integration}

We also explored the descriptive responses to the original 10 items that were included within the survey (Table 3). Most clients agreed with the following: "A good therapist is sensitive to clients' religious/spiritual beliefs" (75.6\%, with 7.3\% disagreeing), and "I would be open to discussing my religious/spiritual beliefs in therapy" $(71.0 \%$, with $12.0 \%$ disagreeing). Clients also largely agreed with "My religious/spiritual beliefs are important to me during difficult times" (65.9\%) and "It is important for my therapist to know how to discuss my religion/spirituality in mental health therapy" (58.9\%). Most clients (51.2\%) reportedly agree that discussing their RS beliefs in treatment improves their mental health outcomes. Finally, over half of clients agreed with 9 out of the 10 reported items, with the exception of whether the therapist should first ask about the client's RS (43.5\%), which still had the highest proportion of positive responses compared with neutral and disagree. In fact, clients were fairly mixed on who should initiate the discussion of RS in therapy, with $43.5 \%$ preferring for the therapist to bring it up and $50.8 \%$ preferring to bring it up themselves. These two items also had a fairly high proportion of neutral respondents $(24.5 \%$ and $28.5 \%$, respectively) compared with the other eight items included within the survey. 
Table 3. Frequencies of Responses to Religious/Spiritually Integrated Practice Assessment Scale-Client Attitudes v2 (RSIPAS-CAv2) items $(n=989)$.

\begin{tabular}{|c|c|c|c|}
\hline RSIPAS-CAv2 Items & $\begin{array}{l}\text { Strongly } \\
\text { Disagree/ } \\
\text { Disagree } \\
n(\%)\end{array}$ & $\begin{array}{l}\text { Neutral } \\
n(\%)\end{array}$ & $\begin{array}{l}\text { Strongly } \\
\text { Agree/ } \\
\text { Agree } \\
n(\%)\end{array}$ \\
\hline $\begin{array}{l}\text { 1. It is important for my therapist to know how to discuss my } \\
\text { religion/spirituality in mental health therapy. }\end{array}$ & $204(20.6)$ & $202(20.4)$ & $583(58.9)$ \\
\hline $\begin{array}{l}\text { 2. My therapist should ask about my religion/spirituality, rather than } \\
\text { wait for me to bring it up. }\end{array}$ & $317(32.1)$ & $242(24.5)$ & $430(43.5)$ \\
\hline $\begin{array}{l}\text { 3. I would prefer to bring up my religion/spirituality, rather than wait } \\
\text { for my therapist to ask about it. }\end{array}$ & $205(20.7)$ & $282(28.5)$ & $502(50.8)$ \\
\hline $\begin{array}{l}\text { 4. Discussing my religious/spiritual beliefs in therapy helps improve } \\
\text { my mental health. }\end{array}$ & $145(24.8)$ & $238(24.1)$ & $506(51.2)$ \\
\hline $\begin{array}{l}\text { 5. When my therapist takes time to understand my religious/spiritual } \\
\text { beliefs, they show greater concern for my well-being rather than not } \\
\text { taking the time to understand my religious/spiritual beliefs. }\end{array}$ & $172(17.4)$ & $247(25.0)$ & $570(57.6)$ \\
\hline $\begin{array}{l}\text { 6. I am open to working with a therapist who has a different belief } \\
\text { system than I do. }{ }^{\text {a }}\end{array}$ & $119(12.0)$ & $197(19.9)$ & $673(68.0)$ \\
\hline 7. A good therapist is sensitive to clients' religious/spiritual beliefs. & $72(7.3)$ & $169(17.1)$ & $748(75.6)$ \\
\hline $\begin{array}{l}\text { 8. I am open to being referred to religious or pastoral counseling if my } \\
\text { therapist thinks it would be helpful. }\end{array}$ & $263(26.6)$ & $175(17.7)$ & $551(55.7)$ \\
\hline $\begin{array}{l}\text { 9. I would be open to discussing my religious/spiritual beliefs } \\
\text { in therapy. }\end{array}$ & $119(12.0)$ & $168(17.0)$ & $702(71.0)$ \\
\hline $\begin{array}{l}\text { 10. My religious/spiritual beliefs are important to me during } \\
\text { difficult times. }\end{array}$ & $181(18.3)$ & $156(15.8)$ & $652(65.9)$ \\
\hline
\end{tabular}

a This item was reported in the table based on the original data collection but was not included in the scale score. It should be removed in future administrations of the RSIPAS-CAv2.

\subsection{Client Characteristics That Predict Positive Attitudes toward Integrating RS}

Using the final, nine-item RSIPAS-CAv2 scale score based on summing each participant's responses to the nine items, univariate and multivariate outliers were detected and removed resulting in a sample size of 949 for the regression. The assumptions for a multiple linear regression of normality, linearity, multicollinearity, and heteroscedasticity were checked and met. There was not a significant relationship between the RSIPAS-CAv2 score and the region of the country they lived in. However, as noted in Table 4, there were significant relationships between the scale score and participants' age, race, gender, frequency of seeing a therapist, whether the client has discussed RS with their current therapist, whether the client identified with an Abrahamic faith tradition, whether they believed in a God/Higher Power, the DUREL NORA and ORA items, and the DUREL intrinsic religiosity subscale.

As shown in Table 4, at the multivariate level, the regression was significant with the following independent variables: age (positively related to an increase in age), gender (inversely related to identifying as female), organized religious activities (positively related to frequency of activity), non-organized religious activities (positively related to frequency of activity), intrinsic religiosity (positively related to an increase in intrinsic religiosity), belief in God/Higher Power (positively related to a belief in God/Higher Power), frequency of therapy attendance (positively related to an increase in attendance), and discussion of RS with their current therapist (positively related to an increase in discussion of RS) $(F[10,938]=136.27, p<0.001)$, with neither race nor faith tradition remaining significant within the regression model. These variables accounted for $59 \%$ of the variance $\left(R^{2}=0.592\right)$, with intrinsic religiosity having the largest influence on the model $(\beta=0.50)$, followed by whether the client has discussed RS with their current therapist $(\beta=0.23)$ (Table 4$)$. 
Table 4. Relationships Between Client Characteristics and Summary of Multiple Regression $(n=949)$.

\begin{tabular}{|c|c|c|c|c|}
\hline \multicolumn{4}{|c|}{ Variable } & $r$ \\
\hline \multicolumn{4}{|c|}{ Age (Continuous) } & $-0.140^{* * *}$ \\
\hline \multicolumn{4}{|c|}{ Race (White or Non-White) } & $-0.118^{* * *}$ \\
\hline \multicolumn{4}{|c|}{ Gender (Female or Non-Female) } & $-0.137^{* * *}$ \\
\hline \multicolumn{4}{|c|}{ Organizing Religious Activity (At least a few times a month or Never/Rarely) } & $0.477^{* * *}$ \\
\hline \multicolumn{4}{|c|}{ Non-Organized Religious Activity (At least once a week or Never/Rarely) } & $0.495^{* * *}$ \\
\hline \multicolumn{4}{|c|}{ Intrinsic Religiosity Score (Continuous) } & $0.698^{* * *}$ \\
\hline \multicolumn{4}{|c|}{ Belief in God/Higher Power (Yes/Unsure or No) } & $0.391^{* * *}$ \\
\hline \multicolumn{4}{|c|}{ Frequency of Seeing Provider (At least a few times a month or Never/Rarely) } & $0.092 * *$ \\
\hline \multicolumn{4}{|c|}{ Faith Tradition (Abrahamic or Non-Abrahamic/None) } & $0.288^{* * *}$ \\
\hline \multicolumn{4}{|c|}{ Have Discussed RS with Current Provider (Yes or No) } & $0.471^{* * *}$ \\
\hline Predictors & B & SE & $\beta$ & $t$-Value \\
\hline Intrinsic Religiosity Score & 1.02 & 0.06 & 0.50 & $16.78^{* * *}$ \\
\hline Have Discussed RS with Current Provider & 3.79 & 0.38 & 0.23 & $10.00^{* * *}$ \\
\hline Age & -0.05 & 0.01 & -0.10 & $-4.51^{* * *}$ \\
\hline Gender (Female) & -1.38 & 0.33 & -0.09 & $-4.22^{* * *}$ \\
\hline Organizing Religious Activity & 1.26 & 0.40 & 0.08 & $3.18^{* *}$ \\
\hline Non-Organized Religious Activity & 1.17 & 0.41 & 0.08 & $2.84 * *$ \\
\hline Frequency of Seeing Provider & 0.82 & 0.35 & 0.05 & $2.35 *$ \\
\hline Belief in God/Higher Power & 1.54 & 0.70 & 0.05 & $2.21 *$ \\
\hline
\end{tabular}

${ }^{*} p<0.05,{ }^{* *} p<0.01,{ }^{* * *} p<0.001 ; R^{2}=0.592 ; R^{2}$ adj $=0.588$.

\section{Discussion}

With 989 respondents from across the US, the current study is the largest, most nationally representative sample of current mental health clients' views regarding RS integration to date. Three key takeaways from this study include (1) most current clients have positive attitudes toward integrating their RS in mental health treatment, (2) among seven predictors of clients' attitudes toward integrating their RS, intrinsic religiosity was the strongest predictor, and (3) the RSIPAS-CAv2 is a reliable and valid tool for assessing current clients' attitudes toward integrating this area of their lives in practice.

First, it is worth highlighting that current clients were more likely to have positive attitudes about integrating their RS in their mental health treatment. Indeed, two out of three clients mentioned their RS beliefs are important to them during difficult times and over half indicated that discussing their RS beliefs in therapy helps improve their mental health. Most clients indicated an openness to discuss their RS in treatment, to work with a therapist with different beliefs than their own, and to being referred to religious or pastoral counseling if the therapist thought it would be helpful. Clients also expressed some expectations of their therapist to be competent in this area, with over half agreeing that it is important for their therapist to know how to discuss clients' RS in therapy and three out of four agreeing a good therapist is sensitive to clients' RS beliefs. These findings suggest RS content is necessary to be included within graduate training programs across disciplines, ensuring providers are equipped to competently meet clients' RS needs and preferences around this area of their lives as it relates to treatment.

The two items that captured client views on who should first bring up RS were mixed. There was a slight preference for clients bringing up RS themselves rather than waiting for the therapist to bring it up (50.8\%), as compared with agreeing that the therapist should ask about the clients' RS rather than wait for the client to bring it up (43.5\%). Both of these items had higher percentages in the agreement category as compared with the disagreement and neutral options, indicating clients are generally split on who should initiate the conversation. Interestingly, other studies have shown many therapists wait for the client to bring up the topic of RS (Oxhandler and Giardina 2017; Oxhandler et al. 2019), which may be preferred by some clients but clearly not by all. Further, this sample of current clients had 7-8\% higher levels of agreement on those two items as compared to the original study, which did not focus on sampling current clients (Oxhandler et al. 
2018b). However, the largest increase in percentages between the original study and current study involved item 4- "Discussing my RS beliefs in therapy helps improve my mental health" - with $39.6 \%$ agreeing to this item in the original study as compared to $51.2 \%$ of current clients agreeing in this study. It is likely this study's focus on sampling current mental health clients and the revised wording to be respondent-focused ("my RS beliefs ... my mental health.") versus clients in general ("Discussing clients' religious/spiritual beliefs in therapy improves client outcomes."; Oxhandler et al. 2018b) both contributed to the increase in levels of agreement.

Next, the regression results indicated that intrinsic religiosity was the strongest predictor of client attitudes toward integrating their RS in treatment, followed by whether they had discussed their RS with the provider, were younger, identified as male, engaged in organized religious activity, engaged in non-organized religious activity, more frequently saw a provider, and believed in God/Higher Power. The two items that were significantly related to the RSIPAS-CAv2 before running the multivariate regression, but were no longer significant within the regression model, were race and faith tradition. Although many of the predictors were congruent with previous studies' findings as described in the introduction, we were surprised that older age and identifying as female were inversely related to attitudes in light of recognizing older adults and women tend to be more religious (Pew Research Center 2015) and have previously reported a desire for integration (Schaffner and Dixon 2003; Stanley et al. 2011). It may be, however, that younger adults and men view RS as being less taboo and are more open to discuss this topic in therapy if it is important to them. It may also be that previous studies showed older age and identifying as female as predictors because of these attributes confounding with their higher levels of religiosity.

Additionally, intrinsic religiosity, or one's motivation to live out their faith (Allport and Ross 1967), emerged as the strongest predictor of positive views toward integrating RS into treatment. This finding matches previous studies, with intrinsic religiosity being the strongest predictor of mental health care providers' views and behaviors around integrating clients' RS in treatment (Oxhandler et al. 2015) and social work educators' views and behaviors around training students to integrate clients' RS in treatment (Oxhandler et al. 2021a). Intrinsic religiosity is clearly an important component in the inclusion of clients' RS in mental health care. Further, it makes sense that clients with higher levels of intrinsic religiosity, infusing it in their everyday lives, would value the integration of RS into their mental health treatment. It was also noteworthy that clients' current discussion of RS in therapy resulted in more positive views toward integrating RS in mental health treatment. It could be that current discussion of this topic with their therapist normalizes and demystifies such inclusion, increasing their positive attitudes toward it, and/or that many clients who have had positive attitudes toward integrating RS in treatment may have been more open to discussing this area of their lives. Further, it is likely that clients may find discussing their RS to be helpful in treatment, particularly with over half of the current sample agreeing that discussing their RS beliefs helps improve their mental health and two-thirds agreeing their RS beliefs are important to them during difficult times. Regardless, our findings suggest there are other client demographic variables to consider at intake aside from or in addition to the typical single item assessing religious affiliation, which was not significant within the regression model. For example, practitioners may consider including the DUREL as part of their intake assessment (Koenig and Büssing 2010) to ask clients about their intrinsic religiosity (especially recognizing how it may influence many areas of their lives, including their clinical issues and circumstances) and organized and non-organized religious activity, as well as ask about their belief in a God or Higher Power.

Finally, the nine-item RSIPAS-CAv2 is a reliable and valid measure that is freely available for mental health care providers and researchers to use. The CFA results indicated an improved fit with this revised version as compared with the first administration of RSIPAS-CA, which did not focus on current clients and may be better used for general 
surveys that do not primarily sample mental health clients (Oxhandler et al. 2018b). We attribute this improved fit and increase in most RSIPAS-CAv2 items' loadings to the slight item wording adjustments to focus on the respondent's own personal experience as well as the sample being limited to current clients. Further, item 6's loading increased from 0.17 in the original study to 0.44 in the current study but did not meet the 0.45 threshold we had set for item retention (Comrey and Lee 1992). We recognize item 6's attention to the therapists' RS is distinct from the other nine items' focus on the clients' RS and recommend it be removed in future administrations of the RSIPAS-CAv2. However, future researchers may want to still include it somewhere within their surveys that use the RSIPAS-CAv2 given the important information it provides around clients' openness to working with therapists with differing RS beliefs and worldviews.

Although this study has a number of strengths, there are limitations worth noting. First, although this method was feasible for obtaining a large, national sample of current clients, Qualtrics' recruitment panel may not be representative of all mental health clients across the US, particularly those without access to technology and/or Qualtrics. Second, given that our sample was largely White and Christian, the views of various minority and historically underrepresented groups may not be fully captured in our sample. However, our sample's RS affiliation, views of being religious or spiritual, and belief in God did match other large-scale samples (Pew Research Center 2015). There is also the chance that those who are not current mental health clients were able to slip into the sample; however, we tried to reduce this risk by including multiple screening questions throughout the survey. Further, there is the risk of acquiescent response bias given that none of the items were reverse-scored. Finally, we acknowledge that the terms religion and spirituality can sometimes be interpreted in various ways and tried to offer consistency in interpretation with definitions at the beginning of the survey. In spite of its limitations, the depth and breadth of the findings in this national study of current mental health clients' attitudes toward integrating their RS in treatment and the potential for these findings to be considered in practice, research, and graduate education speak to the value of this investigation.

\section{Conclusions}

The results from this study indicate that most clients currently engaged in mental health treatment within the US have positive attitudes toward integrating their RS in treatment and that clients' intrinsic religiosity is the top predictor of clients' attitudes toward considering their RS in treatment. We also found the RSIPAS-CAv2 has an improved fit for measuring current mental health clients' attitudes toward integrating their RS in treatment and recommend using this version in future studies of clients. Practitioners and researchers alike may also consider pairing these items with the original RSIPAS-Attitudes subscale (Oxhandler and Parrish 2016) to directly compare client and providers' views toward this area of treatment. Additional research may assess the degree to which clients with diverse experiences, diagnoses, and backgrounds hold varying attitudes toward this area of practice. The degree to which clients consider it to be important for their mental health care provider to have various RS competencies, such as those outlined in Vieten and Scammell (2015), would also be worth exploring in future studies. Recognizing that competently attending to client diversity, including RS diversity, and maintaining a client-centered approach is an important consideration across mental health professions, our hope is that the findings from this study are considered in future practice, research, and graduate training efforts.

Author Contributions: Conceptualization, H.K.O., K.I.P., M.J.P., C.V.; methodology, H.K.O., K.I.P.; validation, H.K.O.; formal analysis, H.K.O.; investigation, H.K.O.; data curation, H.K.O.; writingoriginal draft preparation, H.K.O., K.M.M.; writing-review and editing, H.K.O., K.I.P., M.J.P., C.V.; visualization, H.K.O.; supervision, H.K.O.; project administration, H.K.O., K.I.P.; funding acquisition, K.I.P., H.K.O., M.J.P., C.V. All authors have read and agreed to the published version of the manuscript. 
Funding: This research was funded by the John Templeton Foundation, grant number 60971.

Institutional Review Board Statement: An application for the Institutional Review Board of Baylor University was submitted and considered exempt from review (project 1247833, 23 May 2018) due to this study being an anonymous survey and falling under exemption category.

Informed Consent Statement: Informed consent was obtained from all subjects involved in the study.

Data Availability Statement: The data presented in this study are available from the corresponding author upon reasonable request.

Acknowledgments: The authors would like to thank the John Templeton Foundation (grant \#60971) for their support, and the respondents for their time and willingness to participate in this survey.

Conflicts of Interest: The authors declare no conflict of interest. The funder had no role in the design of the study; in the collection, analyses, or interpretation of data; in the writing of the manuscript; or in the decision to publish the results.

\section{References}

Allport, Gordon W., and J. Michael Ross. 1967. Personal religious orientation and prejudice. Journal of Personality and Social Psychology 5: 432-43. [CrossRef] [PubMed]

American Association for Marriage and Family Therapy. 2012. Code of Ethics. Available online: https://www.aamft.org/Legal_ Ethics/Code_of_Ethics.aspx (accessed on 31 March 2021).

American Counseling Association. 2014. Code of Ethics. July 1. Available online: www.counseling.org/Resources/aca-code-of-ethics. pdf (accessed on 31 March 2021).

American Nurses Association. 2015. Code of Ethics for Nurses with Interpretive Statements. Available online: http:/ / nursingworld. org/codeofethics (accessed on 31 March 2021).

American Psychological Association. 2010. Ethical Principles of Psychologists and Code of Conduct: Including 2010 Amendments. June 1. Available online: www.apa.org/ethics/code (accessed on 31 March 2021).

Arnold, Ruth M., S. Kelly Avants, Arthur Margolin, and David Marcotte. 2002. Patient attitudes concerning the inclusion of spirituality into addiction treatment. Journal of Substance Abuse Treatment 23: 319-26. [CrossRef]

Atkinson, Donald R., and Ruth H. Gim. 1989. Asian-American cultural identity and attitudes toward mental health services. Journal of Counseling Psychology 36: 209-12. [CrossRef]

Baker, Paul, and James Cruickshank. 2009. I am happy in my faith: The influence of religious affiliation, saliency, and practice on depressive symptoms and treatment preference. Mental Health, Religion $\mathcal{E}$ Culture 12: 339-57. [CrossRef]

Bannister, Shaynah N., Hae S. Park, Stephanie Taylor, and Emily N. Bauerie. 2015. Clients' expectations and preferences for marital Christian counseling. A chronological literature review and a contemporary evaluation. Social Work \& Christianity 42: 63-95.

Belaire, Christine, and J. Scott Young. 2002. Conservative Christians' expectations of non-Christian counselors. Counseling and Values 46: 175-87. [CrossRef]

Belaire, Christine, J. Scott Young, and Anastasia Elder. 2005. Inclusion of religious behaviors and attitudes in counseling: Expectations of conservative Christians. Counseling and Values 49: 82-94. [CrossRef]

Carlisle, Patricia. 2015. Religion and spirituality as troublesome knowledge: The views and experiences of mental health social workers in Northern Ireland. British Journal of Social Work 46: 583-98. [CrossRef]

Cashwell, Craig S., J. Scott Young, Tammy H. Cashwell, and Christine Belaire. 2001. The inclusion of spiritual process in counseling and perceived counselor effectiveness. Counseling and Values 45: 145-53. [CrossRef]

Colbert, Linda K., Joseph L. Jefferson, Ralph Gallo, and Ronnie Davis. 2009. A study of religiosity and psychological well-being among African Americans: Implications for counseling and psychotherapeutic processes. Journal of Religious Health 48: 278-89. [CrossRef]

Comrey, Andrew L., and Howard B. Lee. 1992. A First Course in Factor Analysis, 2nd ed. Mahwah: Lawrence Erlbaum.

Crabtree, Sarah A., Chance A. Bell, David A. Rupert, Steven J. Sandage, Nancy G. Devor, and George Stavros. 2020. Humility, differentiation of self, and clinical training in spiritual and religious competence. Journal of Spirituality in Mental Health, 1-21. [CrossRef]

Cragun, Carrie L., and Myrna L. Friedlander. 2012. Experiences of Christian clients in secular psychotherapy: A mixed-methods investigation. Journal of Counseling Psychology 59: 379-91. [CrossRef] [PubMed]

Crosby, James W., and Natasha Bossley. 2012. The religiosity gap: Preferences for seeking help from religious advisors. Mental Health, Religion, and Culture 15: 141-59. [CrossRef]

D'Souza, Russell. 2002. Do patients expect psychiatrists to be interested in spiritual issues? Australian Psychiatry 10: 44-47. [CrossRef]

Daaleman, Timothy P., and Donald E. Nease. 1994. Patient attitudes regarding physician inquiry into spiritual and religious issues. The Journal of Family Practice 39: 564-68. [PubMed]

Erickson, Martin J., Lorna Hecker, Dwight Kirkpatrick, Mark Killmer, and Edassery James. 2002. Clients' perceptions of marriage and family therapists addressing the religious and spiritual aspects of clients' lives: A pilot study. Journal of Family Psychotherapy 12: 109-25. [CrossRef] 
Exline, Julie J. 2013. Religious and spiritual struggles. In APA Handbook of Psychology, Religion, and Spirituality: Context, Theory and Research. Edited by Julie J. Exline, James W. Jones and Kenneth Ira Pargament. Washington, DC: American Psychological Association, pp. 459-75.

Gass, Carlton S. 1984. Orthodox Christian values related to psychotherapy and mental health. Journal of Psychology and Theology 12: 230-37. [CrossRef]

Godwin, Tony C., and Joyce G. Crouch. 1989. Subjects' religious orientation, counselor's orientation and skill, and expectations for counseling. Journal of Psychology and Theology 17: 284-92. [CrossRef]

Guinee, James P., and Terence J. G. Tracey. 1997. Effects of religiosity and problem type on counselor description ratings. Journal of Counseling and Development 76: 65-73. [CrossRef]

Harris, Kevin A., Brooke E. Randolph, and Timothy D. Gordon. 2016. What do clients want? Assessing spiritual needs in counseling: A literature review. Spirituality in Clinical Practice 3: 250-75. [CrossRef]

Hathaway, Stefani. L. 2005. Religious Involvement, Attitudes toward Seeking Professional Psychological Help, and Preferences for Alternative Mental Health Setting. Doctoral dissertation, University of Missouri-Columbia, Columbia, MO, USA, December. Available online: https:/ / pdfs.semanticscholar.org/6fc5/14012d95d34840d56bc3f663cb89faa3a5db.pdf (accessed on 31 March 2021).

Hill, Peter C., Kenneth I. Pargament, Ralph W. Hood, Michael E. McCullough, James P. Swyers, David B. Larson, and Brian J. Zinnbauer. 2000. Conceptualizing religion and spirituality: Points of commonality, points of departure. Journal for the Theory of Social Behaviour 30: 51-77. [CrossRef]

Hodge, David R. 2006. Spiritually modified cognitive therapy: A review of the literature. Social Work 51: 157-66. [CrossRef] [PubMed]

Hook, Joshua N., Everett L. Worthington Jr., Don E. Davis, David J. Jennings, Aubrey L. Gartner, and Jan P. Hook. 2010. Empirically supported religious and spiritual therapies. Journal of Clinical Psychology 66: 46-72. [CrossRef]

Kelly, Eugene W., Amany Aridi, and Laleh Bakhiar. 1996. Muslims in the United States: An exploratory study of universal and mental health values. Counseling and Values 40: 206-18. [CrossRef]

King, Dana E., and Bruce Bushwick. 1994. Beliefs and attitudes of hospital inpatients about faith healing and prayer. Journal of Family Practice 39: 349-52.

Kline, Rex B. 2016. Principles and Practice of Structural Equation Modeling, 4th ed. New York: Guilford.

Knox, Sarah, Lynn Catlin, Margaret Casper, and Lewis Z. Schlosser. 2005. Addressing religion and spirituality in psychotherapy: Clients' perspectives. Psychotherapy Research 15: 287-303. [CrossRef]

Koenig, Harold G., and Arndt Büssing. 2010. The Duke University Religion Index (DUREL): A five-item measure for use in epidemiological studies. Religions 1: 78-85. [CrossRef]

Koenig, Harold G., Dana E. King, and Verna B. Carson. 2012. Handbook of Religion and Health, 2nd ed. Oxford: Oxford University Press.

Koenig, Harold G., Michael E. McCullough, and David B. Larson. 2001. Handbook of Religion and Health. Oxford: Oxford University Press.

Laudet, Alexandre B. 2003. Attitudes and beliefs about 12-step groups among addiction treatment clients and clinicians: Toward identifying obstacles to participation. Substance Use and Misuse 38: 2017-47. [CrossRef]

Leitz, Cynthia A., and David R. Hodge. 2013. Incorporating spirituality into substance abuse counseling: Examining the perspectives of service recipients and providers. Journal of Social Service Research 39: 498-510. [CrossRef]

Leondari, Angeliki, and Vasilios Gialamas. 2009. Religiosity and psychological well-being. International Journal of Psychology 44: 241-48. [CrossRef]

Levin, Jeff. 2016. Prevalence and religious predictors of healing prayer use in the USA: Findings from the Baylor Religion Survey. Journal of Religion and Health 55: 1136-58. [CrossRef] [PubMed]

Lindgren, Karen N., and Robert D. Coursey. 1995. Spirituality and serious mental illness: A two-part study. Psychosocial Rehabilitation Journal 18: 93-111. [CrossRef]

Lukoff, David, Robert Turner, and Francis Lu. 1992. Transpersonal psychology research review: Psychoreligious dimensions of healing. Journal of Transpersonal Psychology 24: 41-60.

Lyon, Rachel E. C., and Christian L. Wimmer. 2005. Spirituality and dream work in counseling: Clients' experiences. Pastoral Psychology 54: 35-45. [CrossRef]

Mayers, Claire, Gerard Leavey, Christina Valliantou, and Chris Barker. 2007. How clients with religious or spiritual beliefs experience psychological help-seeking and therapy: A qualitative study. Clinical Psychology and Psychotherapy 14: 317-27. [CrossRef]

Morrison, Julie Q., Stacy M. Clutter, Elaine M. Pritchett, and Alan Demmitt. 2009. Perceptions of clients and counseling professionals regarding spirituality in counseling. Counseling and Values 53: 183-94. [CrossRef]

Morrow, David, Everett L. Worthington Jr., and Michael E. McCullough. 1993. Observers' perceptions of a counselor's treatment of a religious issue. Journal of Counseling and Development 71: 452-56. [CrossRef]

National Association of Social Workers. 2017. Code of Ethics. Available online: https:/ /www.socialworkers.org/About/Ethics/Codeof-Ethics /Code-of-Ethics-English (accessed on 31 March 2021).

Oxhandler, Holly K., and Kenneth I. Pargament. 2014. Social work practitioners' integration of clients' religion and spirituality in practice: A literature review. Social Work 59: 271-79. [CrossRef]

Oxhandler, Holly K., Danielle E. Parrish, Luis R. Torres, and W. Andrew Achenbaum. 2015. The integration of clients' religion/spirituality in social work practice: A national survey. Social Work 60: 228-37. [CrossRef] 
Oxhandler, Holly K., and Danielle E. Parrish. 2016. The development and validation of the Religious/Spiritually Integrated Practice Assessment Scale. Research on Social Work Practice 26: 295-307. [CrossRef]

Oxhandler, Holly K., and Traber D. Giardina. 2017. Social workers' perceived barriers to and sources of support with integrating clients' religion/spirituality in practice. Social Work 62: 323-32. [CrossRef]

Oxhandler, Holly K. 2017. Namaste theory: A quantitative grounded theory on religion and spirituality in mental health treatment. Religions 8: 168. [CrossRef]

Oxhandler, Holly K., and Danielle E. Parrish. 2018. Integrating clients' religion/spirituality in clinical practice: A comparison among social workers, psychologists, counselors, marriage and family therapists, and nurses. Journal of Clinical Psychology 74: 680-94. [CrossRef]

Oxhandler, Holly K., Edward C. Polson, and W. Andrew Achenbaum. 2018a. The religiosity and spiritual beliefs and practices of clinical social workers: A national survey. Social Work 63: 47-56. [CrossRef] [PubMed]

Oxhandler, Holly K., James W. Ellor, and Matthew S. Stanford. 2018b. Client attitudes toward integrating religion/spirituality in mental health treatment: Scale development and client responses. Social Work 63: 337-46. [CrossRef]

Oxhandler, Holly K., Edward C. Polson, and Kelsey M. Moffatt. 2021a. The Religious/Spiritually Integrated Practice Assessment Scale for Educators: A national survey of social work faculty. Journal of Social Work Education. In press.

Oxhandler, Holly K., Kenneth I. Pargament, Michelle J. Pearce, Cassandra Vieten, and Kelsey M. Moffatt. 2021b. The perceived relevance of religion/spirituality and mental health to one another: A national survey of current clients' views and scale development. Social Work. In press.

Oxhandler, Holly K., Kelsey M. Moffatt, and Traber D. Giardina. 2019. Clinical helping professionals' perceived support, barriers, and training to integrate clients' religion/spirituality in practice. Spirituality in Clinical Practice 6: 279-91. [CrossRef]

Pargament, Kenneth I. 2007. Spiritually Integrated Psychotherapy: Understanding and Addressing the Sacred. New York: Guilford Press.

Pargament, Kenneth I., Annette M. Mahoney, Julie J. Exline, James W. Jones, and Edward P. Shafranske. 2013. Envisioning an integrative paradigm for the psychology of religion and spirituality. In APA Handbook of Psychology, Religion, and Spirituality: Context, Theory and Research. Edited by Kenneth I. Pargrament, Julie J. Exline and James W. Jones. Washington, DC: APA, pp. 3-19.

Pearce, Michelle J. 2016. Cognitive Behavioral Therapy for Christians with Depression: A Practical Tool-Based Primer. West Conshohocken: Templeton Press.

Pearce, Michelle J., Kenneth I. Pargament, Holly K. Oxhandler, Cassandra Vieten, and Serena Wong. 2020. Novel online training program improves spiritual competence in mental health care. Spirituality in Clinical Practice 7: 145-61. [CrossRef]

Pew Research Center. 2012. “Nones” on the Rise. Available online: https://www.pewforum.org/2012/10/09/nones-on-the-rise/ (accessed on 31 March 2021).

Pew Research Center. 2015. U.S. Religious Landscape Study. Available online: http:/ / www.pewforum.org/religious-landscape-study/ (accessed on 31 March 2021).

Post, Brian C., and Nathaniel G. Wade. 2009. Religion and spirituality in psychotherapy: A practice-friendly review of research. Journal of Clinical Psychology 65: 131-46. [CrossRef]

Post, Brian C., Nathaniel G. Wade, and Marilyn A. Cornish. 2014. Religion and spirituality in group counseling: Beliefs and preferences of university counseling center clients. Group Dynamics: Theory, Research, and Practice 18: 53-68. [CrossRef]

Privette, Gayle, Stephen Quackenbos, and Charles M. Bundrick. 1994. Preferences for religious or nonreligious counseling and psychotherapy. Psychological Reports 75: 539-46. [CrossRef] [PubMed]

Rogers, Edward B., Matthew Stanford, and Diana R. Garland. 2012. The effects of mental illness on families within faith communities. Mental Health, Religion \& Culture 15: 301-13. [CrossRef]

Rose, Elizabeth M., John S. Westefeld, and Timothy N. Ansley. 2001. Spiritual issues in counseling: Client's beliefs and preferences. Journal of Counseling Psychology 48: 61-71. [CrossRef]

Schaffner, Angela D., and David N. Dixon. 2003. Religiosity, gender, and preferences for religious interventions in counseling: A preliminary study. Counseling and Values 48: 24-33. [CrossRef]

Smith, Timothy B., Jeremy Bartz, and P. Scott Richards. 2007. Outcome of religious and spiritual adaptations to psychotherapy: A meta-analytic review. Psychotherapy Research 17: 643-55. [CrossRef]

Smith, Tom W., Michael Hout, and Peter Marsden. 2016. General Social Surveys, 1972-2014 Cumulative File. Chicago: National Opinion Research Center, University of Chicago.

Stanley, Melinda A., Amber L. Bush, Mary E. Camp, John P. Jameson, Laura L. Philips, Catherine R. Barber, Darrell Zeno, James W. Lomax, and Jeffrey A. Cully. 2011. Older adults' preferences for religion/spirituality in treatment for anxiety and depression. Aging and Mental Health 15: 334-43. [CrossRef] [PubMed]

Tepper, Leslie, Steven A. Rogers, Esther M. Coleman, and H. Newton Malony. 2001. The prevalence of religious coping among persons with persistent mental illness. Psychiatric Services 52: 660-65. [CrossRef]

van Nieuw Amerongen-Meeuse, Joke C., Hanneke Schaap-Jonker, Christa Anbeek, and Arjan W. Braam. 2020. Religious/spiritual care needs and treatment alliance among clinical mental health patients. Journal of Psychiatric and Mental Health Nursing $28: 370-83$. [CrossRef]

Vieten, Cassandra, and Shelley Scammell. 2015. Spiritual and Religious Competencies in Clinical Practice: Guidelines for Psychotherapists and Mental Health Professionals. Oakland: New Harbinger. 
Wade, Nathaniel G., Everett L. Worthington Jr., and David L. Vogel. 2007. Effectiveness of religiously tailored interventions in Christian therapy. Psychotherapy Research 17: 91-105. [CrossRef]

Walker, Donald F., Everett L. Worthington Jr., Aubrey L. Gartner, Richard L. Gorsuch, and Evalin R. Henshew. 2011. Religious commitment and expectations about psychotherapy among Christian clients. Psychology of Religion and Spirituality 3: 98-114. [CrossRef]

Wang, Philip S., Michael Lane, Mark Olfson, Harold A. Pincus, Kenneth B. Wells, and Ronald C. Kessler. 2005. Twelve-month use of mental health services in the United States: Results from the national comorbidity survey replication. Archive of General Psychiatry 62: 629-40. [CrossRef] [PubMed]

Weld, Chet, and Karen Eriksen. 2007. The ethics of prayer in counseling. Counseling and Values 51: 121-38. [CrossRef]

Wikler, Meir. 1989. The religion of the therapist: Its meaning to Orthodox Jewish clients. The Hillside Journal of Clinical Psychiatry 11: 131-46. [PubMed]

Worthington, Everett L., Jr., Joshua N. Hook, Don E. Davis, and Michael A. McDaniel. 2011. Religion and spirituality. Journal of Clinical Psychology 67: 204-14. [CrossRef] 